\title{
Does Inquiry-based Education Using Robots Have an Effect on Learners' Inquiry Skills, Subject Knowledge and Skills, and Motivation?
}

\author{
Margus Pedaste ${ }^{\mathrm{a}}$, Heilo Altin ${ }^{\mathrm{b}}$ \\ ${ }^{a}$ Institute of Education, University of Tartu, Salme 1a, Tartu, 50103, Estonia \\ E-mail:margus.pedaste@ut.ee \\ ${ }^{b}$ Institute of Computer Science, University of Tartu, Liivi 2, Tartu, 50409, Estonia \\ E-mail: heilo.altin@ut.ee
}

\begin{abstract}
Robots have been applied in science education for a long time. Inquiry-based learning, as a student-centred method to discover different relations, has been considered as an effective learning approach in science education and robots are often used to apply student-guided inquiry. It is, however, not clear what the effect of inquiry-based scenarios is in learning science when students' motivation and novelty effect are taken into account. In our study, we tested seven inquiry-based scenarios in secondary school physics with a sample of 47 students in the experiment classes and 41 in the control classes. Results revealed that the inquire-based scenarios improved students' inquiry skills and subject knowledge and skills in the case of the experiment classes and also in the case of the control classes. Study motivation did not improve in the study, explained by the fact that the schools have used robots previously in learning and the novelty effect has faded out. Based on our discussion, the use of robots in education needs to focus more on supporting students' thinking activities and on increasing their awareness about their own skills and learning process. Further studies are needed to understand in-depth how teachers' activities in the classroom might have an effect on the usability of robots in education and how students' thinking and awareness of the learning process could be improved in order to have a stronger effect on learning outcomes as well.
\end{abstract}

Keywords — robotics education; inquiry-based learning; inquiry skills; study motivation; physics learning.

\section{INTRODUCTION}

Robots have been applied in education since the 1980s starting from the construction of objects [1] and the use of social robots [2], [3] to a large variety of uses [4]. The initial idea of using robots in science education mainly originated from Seymour Papert who defined constructionism as enabling a person to learn with objects [5]. When people use their hands, they simultaneously construct thoughts in their brain. When objects are more personal, people are more motivated and obtain deeper learning. Constructionism could be seen as an implementation of constructivism, as introduced by Piaget. According to constructivism, knowledge cannot be transferred to the brain, as data is copied from one hard drive to another. Instead, knowledge is created in the brain. Despite educational theories supporting the use of technology in the classroom having been around for a long time, no widespread solution to use robots in education was available until LEGO released Mindstorms RCX in 1998. For example, nowadays robots could be used in gamifying learning process, and this might have a positive effect on learning outcomes, as revealed in the study of Lindberg [6].

Educational robotics has been actively used in Estonian schools for more than ten years. Nowadays more than $70 \%$ of schools are equipped with educational robotics platforms. Robots are mostly used in extracurricular activities that do not enable pupils' wide access to robotics and exclude the use of robots in formal education. The number of robots per school varies, but there are a few examples where schools are able to give courses with robots to all pupils in one class. Another challenge is an increasing variety of available tools in the last years. The variety of educational robotics might not be an issue in itself, but schools start to collect different platforms believing that educational innovation is born out of getting to know another tool. Alimisis [7] has stated that educational innovation is based on balance of hardware and proper methodology. Focusing only on hardware will not allow neither the teacher nor the pupil to go deeper with the robot and solve more complex problems. The learning curve 
is much higher when a robot is used as a tool not as an object. The problem is that although there are many tools available, their use does not focus on developing skills and enhancing formal education. The purpose of educational robotics in Estonia is not to make STEM popular and build more engineers, but it is to give every child an opportunity to become an engineer and to develop future skills. These future skills are embedded in STEM and with an evolving world where technology increasingly surrounds society, people need to have these skills. Pedaste and Leijen [8] have showed how advanced technologies support a contemporary learning approach and conclude, in their review, that technologies are mainly designed to acquire subject knowledge and skills. Future oriented learning skills and subjective well-being, a pre-requisite for learning, are often not supported. In STEM professions, problem solving skills [9], inquiry skills [10], and computational thinking skills [11][12] are needed, and for that reason we also focused on these skills in our study.

As Seymour Papert defined the subject math as a tool of cognition, robotics could just as well have the same role in a curriculum today. In our study, robotics is a tool with a proper methodology to develop inquiry and problem solving skills. We also see that inquiry is an important method to improve students learning outcomes in the cognitive domain - in acquiring subject specific knowledge and skills. The positive effect of inquiry-based learning has been revealed even in large scale studies like PISA [13] where the nature of inquiry activities has not been controlled. Robots could be seen to support inquiry-based learning as tools to increase learning motivation and to help reach deeper levels of learning [1][14]. Knowledge about the subject could be taken as a horizontal result over the subject where robots are used. However, in order to go deeper with learning and to increasing learners' intrinsic motivation towards learning, the use of robots should also ensure a certain level of pupil autonomy [15]. Therefore, we also have to understand how educational robotics supports autonomy, which is, according to the self-determination theory [16], one of the foundations for motivation. Self-determination theory states three psychological needs required for the formation of motivation: perceived competence, autonomy, and relatedness. We hypothesize in our study that giving pupils more autonomy with robots leads to deeper learning and as a result better knowledge about the subject. In order to test this hypothesis, we used robots as tools for learning in learning scenarios which enable assignments focusing on deeper learning of inquiry and problem-solving skills in addition to knowledge about the subject. Our guiding research question was the following: how the use of robots in formal lessons of physics affect pupils' inquiry and problem solving skills, knowledge about the subject, and motivation towards learning? More specifically, three research questions were formulated:

- How did pupils improve their inquiry skills, content knowledge and skills, and motivation in applying scenarios using robots to learn physics?

- What are the variables predicting pupils' inquiry skills in applying scenarios using robots to learn physics?
- What are the variables predicting improvement of pupils' content knowledge and skills in applying scenarios using robots to learn physics?

\section{MATERIAL AND METHOD}

\section{A. Intervention}

In this study we aimed to provide new robotics-oriented methods for learning seven topics of physics in the national curriculum in Estonia for ages 16-18. The selected topics were the following:

- Acceleration

- Newton's second law

- Strength of the cable measured by pulling force

- Angular velocity

- Impulse momentum

- Pendulum

- Forces of friction

The national curriculum in Estonia does not limit the methods teachers need to use for teaching. We invited two schools to participate in our study to test the new methods for learning physics using robots. Both schools had teachers who have experience using robotic devices in their teaching. The schools were selected based on their own willingness to try out experimental approach in physics teaching.

In both schools, a control and an experiment class were chosen. The control class learned the physics topics in a traditional way, i.e. the usual methods the teacher had been using to teach physics. The sample of the study consisted of 88 students, 47 in the experiment classes and 41 in the control classes. Teachers explained during the post-study interviews that traditional methods are based on learning formulas and concepts from text- and workbooks.

An experimental approach to the selected physics' topics was built only using worksheets with LEGO Mindstorms EV3 base and custom models. Worksheets were interactive PDF files that followed an inquiry learning method introduced by Pedaste et al. [10]. Pupils had to understand the problem, raise an inquiry question, form an hypothesis, collect data with the robotic tool, analyze the data and form conclusions. The work with robots and the developed worksheet supported pupil's bigger autonomy and hypothetically would lead to increased motivation and deeper learning towards the topic. Teacher intervention was minimal including technical aid and managing time and tasks. Some worksheets did not present a formula, but guided pupils to find it out themselves. The pupils were asked to work in pairs. Each pair of pupils had to work with one robot and a worksheet. Although each pupil having a personal robot would probably increase a pupil's motivation even more, the lack of hardware sets the limit. Experience of practitioner over the years of educational robotics in Estonia shows one robot per two pupils' ratio to be most optimal.

Robotic tools in the experiments were built using the LEGO Mindstorms EV3 platform and Vernier sensors that connect to the robot controllers. In five experiments, only the robot was used. In two experiments, in forces of friction and strength of the cable, Vernier force sensor were connected to the robot to measure forces in the experiment and values were displayed as a graph on the computer screen. A reason for carrying out the experiment as 
described above is to provide a simple and easy to use tool for STEM teachers to enhance their lessons. The main focus is minimal preparation time and plug \& play technology.

The main purposes of the experiments were to increase inquiry and problem-solving skills and help pupils better understand physics concepts compared to traditional learning methods. After experiment classes completed all the experiments, pupils filled in the post-test measuring the same skills as the pre-test. The control class followed the same procedure as the experiment class. We also studied motivation towards learning. Seymour Papert [5] has shown how hands-on tools affect the creation of knowledge with constructionism theory. Knowledge created using the constructionist approach has more connections in the human brain and is therefore remembered longer. Effect and motivation are even stronger when knowledge is created with an object that is personal to users. Constructionism together with inquiry learning and robotics will create new synergy that would enable better learning results and increase the motivation of pupils towards STEM subjects.

\section{B. Data collection and quality of instruments}

We used a test to assess inquiry skills and content knowledge and skills in physics. This test was developed in the context of our study and therefore we first had to conduct an analysis of the quality of the test with IRT analysis and the structure of the test with confirmatory factor analysis. Learners' motivation, autonomy, and learning strategies were assessed using tests that have previously been validated, but we controlled the expected factor structure of these in the context of our study.

One-parameter IRT (Item Response Theory) analysis was used to evaluate the quality of the test measuring inquiry skills and also content knowledge and skills. IRT allows evaluating the quality of each test item. IRT analysis was conducted using WINSTEPS 4.0.1. We used 29 items in the pre-test and 29 items in the post-test. 11 items measured inquiry skills and 18 items content knowledge and skills. First, the test difficulty was checked. The result of the check indicated that the test is rather more difficult than more simple for the pupils: difficulty measure -.35 . However, the score did not indicate that the test would be too difficult for the target group. Next, the test's reliability was calculated and this was .84 . This shows how stable the difficulty of the test items is for different respondents.

Further, item level quality was tested. The items used for measuring inquiry skills were the same in the pre- and posttest, but the context of the questions was changed. Items for measuring content knowledge and skills were usually the same, only in the case of two items was the number changed to be used in making calculations, and one item was different in the pre- and post-test. IRT analysis showed that most of the items differentiate pupils well. As estimated by the IRT model, 1.0 is considered to be ideal discrimination. Useful test items should have discrimination scores between .5 and 2.0. In our item list, there were five items in the pre-test and four items in the post-test that were with a discrimination score below .5 and these were left out from our following analyses. Next, we analysed the item fit measure of the test items. It was tested by a correlation coefficient that shows how well the scores of each item are in line with the expected difficulty level of these items in the test. We used a threshold of .20 for acceptable items, as suggested in the Winsteps manual. It appeared that all items were with good fit.

Confirmatory Factor Analysis was used to test the quality of the instruments used in the study: for measuring inquiry skills, content knowledge and skills, motivation, and learning strategies.

1) Inquiry Skills: There were 11 items to measure pupils' inquiry skills in the pre- and post-test. The 11 items were measured with six questions. One question gave answers to three linked questions - pupils had to formulate a research question, and it was coded as three items: correctness of formulation, recognition of independent variable, and recognition of dependent variable. Similarly, the question for formulating hypothesis was coded as four items. The questions were the same in both tests (e.g. formulate a research question), but the topic was a bit different. Confirmatory factor analysis was used to check the factor structure. Two hypotheses were checked: i) two-factor structure of the data according to what planning (formulation of research questions and hypotheses) is a separate factor from the implementation (analysis of data and making conclusions), ii) one-factor structure.

The analysis of the two-factor model gave good fit indices $\left(\chi^{2} / \mathrm{df}=1.77\right.$, RMSEA $=.066$, CFI $=.967$, TLI $=.941$, SRMR = .070); however, there was a strong correlation between the two factors (standardized correlation coefficient .858) and the model was rejected. The one factor model had similar fit indices $\left(\chi^{2} / \mathrm{df}=1.79, \mathrm{RMSEA}=.067\right.$, $\mathrm{CFI}=.965, \mathrm{TLI}=.939, \mathrm{SRMR}=.071)$ and was further used in the analysis. Ten items were used in the final model. Further, item level quality was tested. The items used for measuring inquiry skills were the same in the pre- and posttest, but the context of the questions was changed. Items for measuring content knowledge and skills were usually the same, only in the case of two items was the number changed to be used in making calculations, and one item was different in the pre- and post-test. IRT analysis showed that most of the items differentiate pupils well. In our item list, there were five items in the pre-test and four items in the post-test with discrimination score below .5 and these were left out from our following analyses. Next, we analysed the item fit measure of the test items. It was tested by a correlation coefficient that shows how well the scores of each item are in line with the expected difficulty level of these items in the test. It appeared that all items were with good fit.

2) Content Knowledge and Skills: There were 19 items to measure pupils' content knowledge and skills in the preand post-test. The items were about physics topics in focus of the robotics intervention. There were two hypotheses about the structure of the items. The first hypothesis was a three-factor model differentiating items measuring knowledge, understanding, and application. The confirmatory factor analysis did not support this hypothesis - there was no convergence when the expected number of iterations exceeded. The one-factor had poor quality according to some of the fit indices $\left(\chi^{2} / \mathrm{df}=1.59\right.$, RMSEA $=.058, \mathrm{CFI}=.668, \mathrm{TLI}=.623, \mathrm{SRMR}=.088)$. Ten out of 
19 items had a low factor loading (below .3) and, therefore, these were left out from the model. The adjusted model had a good fit $\left(\chi^{2} / \mathrm{df}=1.36\right.$, RMSEA $=.045, \mathrm{CFI}=.943$, TLI $=.918, \mathrm{SRMR}=.080)$ and nine items describing this model were used in the following analyses.

3) Motivation: There were 21 items to characterize pupils' motivation. The items were translated and adapted from the SMQ-II instrument (https://coe.uga.edu/assets/downloads/mse/smqii-glynn.pdf) The instrument consisted of five dimensions: intrinsic motivation, self-efficacy, self-determination, grade motivation, and career motivation. The instrument was designed to take into account extensive analysis of other instruments used for evaluating students' motivation in science. In our study, only one item was selected for describing grade motivation, as it was not in the focus of the study. Five items were used in case of all other dimensions and the model with these dimensions had only moderate fit $\left(\chi^{2} / \mathrm{df}=2.45\right.$, RMSEA $=.091, \mathrm{CFI}=.878, \mathrm{TLI}=.858$, SRMR $=.085)$. Based on the analysis of the model, it was decided to leave out one item and to allow two correlations between items within one dimension. The adjusted model had a good fit $\left(\chi^{2} / \mathrm{df}=1.96, \mathrm{RMSEA}=.074, \mathrm{CFI}=.925\right.$, TLI $=.911, \mathrm{SRMR}=.078)$ and the items describing this model were used in our following analyses (19 items). We also checked if these four dimensions of motivation can be merged in the analysis into one factor, but the data did not support this. Therefore, these dimensions were used separately in the analyses.

4) Learning Strategies: Learning strategies were characterized using a higher-order factor model of four factors that were combined into two higher-order factors. The factors were selected according to the relevance in the study from Vermunt [17]. The first higher-order factor described deep processing, and it consisted of factors i) relating and structuring and ii) critical processing. The second higher-order factor was stepwise processing consisting of the factors i) memorizing and rehearsing and ii) analyzing. The number of items in the factors varied from four to seven. Learning strategies were only measured before the intervention.

First, the four-factor model was tested with confirmatory factor analysis. The model fit was not good according to some fit indices $\left(\chi^{2} / \mathrm{df}=1.77, \mathrm{RMSEA}=.094, \mathrm{CFI}=.865\right.$, $\mathrm{TLI}=.847, \mathrm{SRMR}=.082)$ and the correlation between some of the factors was too high. Therefore, the model was adjusted leaving out three items and allowing two correlations between items within one dimension. The adjusted model had a good fit $\left(\chi^{2} / \mathrm{df}=1.42\right.$, RMSEA $=.069$, $\mathrm{CFI}=.935, \mathrm{TLI}=.923, \mathrm{SRMR}=.063$ ) but the standardized correlations between critical processing and memorizing and rehearsing, and critical processing and analysing were still above .8. However, we decided to use this model further in the study as the model had been used in several other studies, and our sample was a bit small to get strong pieces of evidence for rejecting the model. Next, we tested if the higher-order model could be described based on the four identified factors. The higher-order model had a good fit according to fit indices $\left(\chi^{2} / \mathrm{df}=1.45\right.$, RMSEA $=.071, \mathrm{CFI}$ $=.931, \mathrm{TLI}=.919, \mathrm{SRMR}=.066)$ and, therefore, it was also possible to use deep learning strategy as one higher-order factor.

The autonomy of pupils was characterized by three items selected from the Intrinsic Motivation Inventory developed and tested by McAuley, Duncan, and Tammen [18]. The test was used only before the intervention to use autonomy as a variable in understanding the learning situation. The model was identified in confirmatory factor analysis, but with zero degrees of freedom and, therefore, it was not possible to assess the model fit. All three items had high factor loadings, and we decided to use them in our following analyses.

\section{Analysis to Answer Research Questions}

First, data were checked for normality. Only five items out of 24 used in the analysis appeared to be normally distributed. Therefore, non-parametric statistical analyses for describing changes in pupils' inquiry skills, content knowledge and skills, and pupils' motivation was used. The analyses were conducted using IBM SPSS Statistics Version 25.

The research questions about predicting improvement of inquiry skills and content knowledge and skills were answered using structural equation modeling. MPlus software (Version 7; Muthen \& Muthen, 1998-2015) was used for these analyses, but we can only demonstrate trends that need to be studied further in studies where the sample is larger and as a result, a normal distribution of the data could be expected.

\section{RESULTS AND DISCUSSION}

Wilcoxon Signed Rank test showed that both pupils' inquiry skills and content knowledge and skills improved statistically significantly in using the intervention. However, their motivation did not change in any of the four aspects distinguished in our study (see Table I).

The experiment and the control group did not show any statistically significant differences in the improvement of the assessed constructs based on Mann-Whitney U test (see Table II).

TABLE I

IMPROVEMENT OF PUPILS' INQUIRY SKILLS, CONTENT KNOWLEDGE AND SKILLS, AND MOTIVATION IN THE PHYSICS LESSONS OF THE EXPERIMENT

\begin{tabular}{|l|l|l|l|l|l|}
\hline Variable & $\begin{array}{l}\text { Negative } \\
\text { ranks }\end{array}$ & $\begin{array}{l}\text { Positive } \\
\text { ranks }\end{array}$ & Ties & $\mathbf{Z}$ & $\mathbf{p}$ \\
\hline Inquiry skills & 10 & 76 & 1 & -6.78 & $<.001$ \\
\hline $\begin{array}{l}\text { Content } \\
\text { knowledge and } \\
\text { skills }\end{array}$ & 16 & 69 & 2 & -6.02 & $<.001$ \\
\hline $\begin{array}{l}\text { Intrinsic } \\
\text { motivation }\end{array}$ & 36 & 35 & 16 & -.16 & n.s. \\
\hline Self-efficacy & 37 & 35 & 15 & -1.08 & n.s. \\
\hline $\begin{array}{l}\text { Self-determi- } \\
\text { nation }\end{array}$ & 33 & 35 & 19 & -.54 & n.s. \\
\hline $\begin{array}{l}\text { Career } \\
\text { motivation }\end{array}$ & 37 & 34 & 16 & -.37 & n.s. \\
\hline
\end{tabular}

TABLE II

COMPARISON OF EXPERIMENT AND CONTROL GROUP IMPROVEMENT IN INQUIRY SKILLS, CONTENT KNOWLEDGE AND SKILLS, AND MOTIVATION IN THE PHYSICS LESSONS OF THE EXPERIMENT

\begin{tabular}{|l|l|l|l|l|}
\hline Variable & $\begin{array}{l}\text { Mean rank - } \\
\text { Control group }\end{array}$ & $\begin{array}{l}\text { Mean rank - } \\
\text { Experiment group }\end{array}$ & $\mathbf{Z}$ & $\mathbf{p}$ \\
\hline Inquiry skills & 42.56 & 46.19 & .51 & n.s. \\
\hline
\end{tabular}




\begin{tabular}{|l|l|l|c|c|}
\hline $\begin{array}{l}\text { Content } \\
\text { knowledge and } \\
\text { skills }\end{array}$ & 45.21 & 43.88 & .81 & n.s. \\
\hline $\begin{array}{l}\text { Intrinsic } \\
\text { motivation }\end{array}$ & 44.59 & 44.43 & .98 & n.s. \\
\hline Self-efficacy & 42.45 & 46.29 & .48 & n.s. \\
\hline $\begin{array}{l}\text { Self- } \\
\text { determination }\end{array}$ & 46.09 & 43.12 & .58 & n.s. \\
\hline $\begin{array}{l}\text { Career } \\
\text { motivation }\end{array}$ & 41.91 & 46.76 & .37 & n.s. \\
\hline
\end{tabular}

A. What are the variables predicting pupils' inquiry skills?

Two models were tested. The first model tested how different variables can predict the improvement of inquiry skills. In the second model, the inquiry skills in the post-test were predicted. The models (see Table III) were not with acceptable fit indices, and only a few variables predicted the inquiry skills statistically significantly; however, the models show some trends that need to be studied further.

TABLE III

SEM MODELS PREDICTING INQUIRY SKILLS

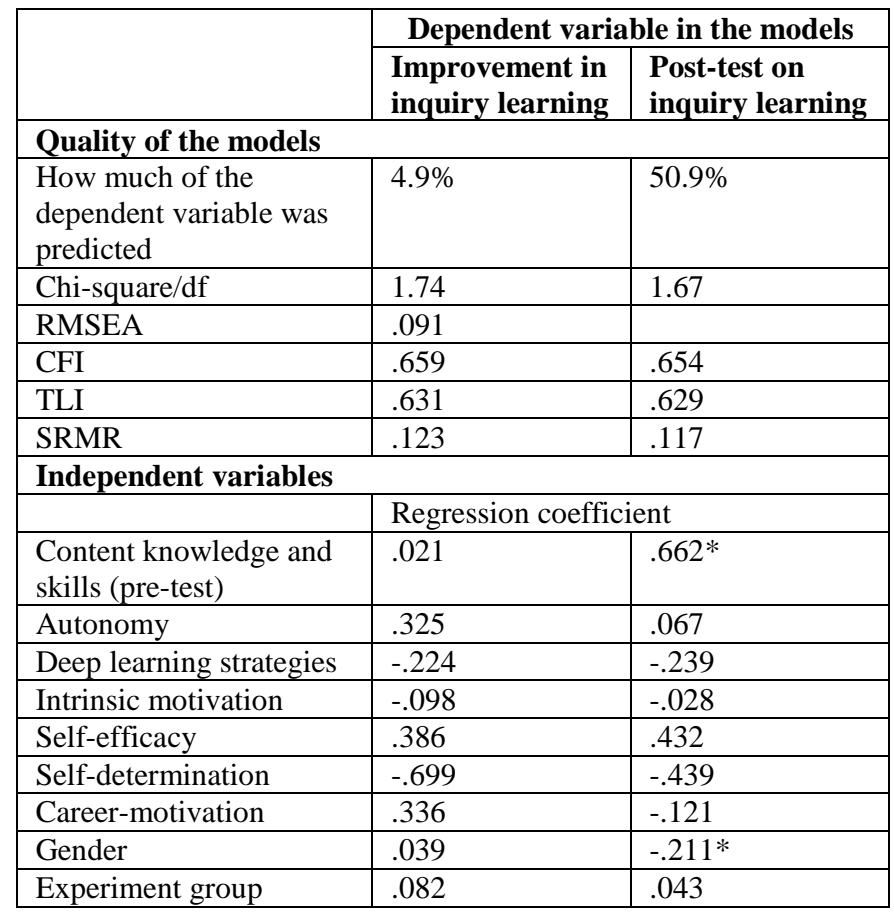

*statistically significant regressions

Interesting differences were seen in comparing regression coefficients when predicting improvement vs post-test results on inquiry learning. For example, pre-test content knowledge and skills did not predict the improvement of inquiry learning skills but predicted statistically significantly the post-test results. Pupils' autonomy and career-motivation seemed to predict improvement of inquiry skills but did not predict the post-test results. Gender did not predict improvement but predicted post-test results. It is also remarkable that self-efficacy seemed to predict higher learning gain and post-test achievement in inquiry skills, but self-determination had a negative effect on both of them.

B. What are the variables predicting improvement of pupils' content knowledge and skills?

Two models were tested. The first model tested how improvement of content knowledge and skills can be predicted by different variables. The second model predicted content knowledge and skills in the post-test. There was no convergence in the case of these models as the maximum number of iterations was exceeded and, therefore, the models show only some trends that need to be studied further (see Table IV).

TABLE IV

SEM MODELS PREDICTING CONTENT KNOWLEDGE AND SKILLS

\begin{tabular}{|l|l|l|}
\hline \multirow{2}{*}{} & \multicolumn{2}{|c|}{ Dependent variable in the models } \\
\cline { 2 - 3 } & $\begin{array}{l}\text { Improvement in } \\
\text { content } \\
\text { knowledge and } \\
\text { skills }\end{array}$ & $\begin{array}{l}\text { Post-test in } \\
\text { content } \\
\text { knowledge and } \\
\text { skills }\end{array}$ \\
\hline Quality of the models \\
\hline $\begin{array}{l}\text { How much of the } \\
\text { dependent variable was } \\
\text { predicted }\end{array}$ & $63.0 \%$ & $50.5 \%$ \\
\hline Chi-square/df & $\begin{array}{l}\text { No convergence. } \\
\text { The number of } \\
\text { iterations exceeded. }\end{array}$ & $\begin{array}{l}\text { No convergence. } \\
\text { The number of } \\
\text { iterations exceeded. }\end{array}$ \\
\hline Independent variables & \multicolumn{2}{|l}{} \\
\hline \multicolumn{2}{|l|}{} & Regression coefficient \\
\hline Inquiry skills (pre-test) & -.141 & -.223 \\
\hline Autonomy & -.005 & -.011 \\
\hline $\begin{array}{l}\text { Deep learning } \\
\text { strategies }\end{array}$ & .003 & -.138 \\
\hline Intrinsic motivation & -.878 & .636 \\
\hline Self-efficacy & .073 & -.490 \\
\hline Self-determination & -.071 & .320 \\
\hline Career-motivation & .208 & .119 \\
\hline Gender & .036 & .160 \\
\hline Experiment group & -.028 & -.037 \\
\hline & & \\
\hline
\end{tabular}

Interesting differences are seen in comparing regression coefficients when predicting improvement vs post-test results on content knowledge and skills. For example, intrinsic motivation has a strong negative regression on improvement in content knowledge and skills but a positive effect on the post-test results. In contrast, self-efficacy cannot predict learning gain but has a positive effect on posttest results.

Some interesting findings can also be seen when comparing how the same variables predict inquiry skills vs content knowledge and skills. If intrinsic motivation has a strong positive effect on the post-test results of content knowledge and skills, then it does not have an effect on inquiry skills. Self-efficacy, however, has a positive effect on post-test inquiry skills results but a negative effect on content knowledge and skills. Self-determination also has a different effect on these dependent variables.

\section{General discussion}

Based on the results of the analysis, we cannot fully confirm the hypothesis that the use of robots would increase pupil's inquiry and problem-solving skills, knowledge about the subject, and motivation towards learning. Indeed, the Wilcoxon Signed Rank test showed statistically significant improvement in inquiry, content knowledge, and skills, but this was also the case for the control group. This shows that robots are at least an alternative to the more traditional methods to learn physics in secondary school. Thus, the model of educational robotics introduced by Altin and Pedaste [1] has been somewhat justified with our empirical 
findings. There is no better or worse effect on learning gain. It was also interesting that the use of robots did not have an effect on learning motivation. This might be explained by the fact that the schools which participated in the study have used robots in their learning process for a longer period of time. Therefore, a significant novelty effect is missing, and robots are perceived by students as one tool for learning, among others. Therefore, we could believe that our study reveals that the technology in itself does not have a positive effect on motivation when the novelty effect has faded out. The effect on learning motivation, when using robots in learning physics, needs to be investigated further as several other studies have shown a positive effect of educational robotics on motivation, e.g. [19]-[22].

We also acknowledge that our study has some limitations and, therefore, further studies are needed to better understand the processes of how robots could be even more effectively used in inquiry-based science learning. For example, our sample was small and conducted in schools, and with physics teachers, we already knew. These teachers have generally been active in STEM educational activities and might do more than teachers usually do in their classes. Thus, the results with less motivated teachers might not be as supportive and might need more scaffolding in applying the innovative method to learn with technologies. The same has recently been found in the analysis of the effect of inquiry-based instruction [23]. In addition, it is important to study further the exact classroom activities that were not observed in our study. It might reveal the benefits of inquirybased use of robots in comparison with more traditional methods. For example, Dobber [24] found in their metaanalysis of 186 studies that teachers might have a very crucial role in metacognitive, conceptual, and social regulation important to benefit from the inquiry approach. However, a more specific procedure also gives more control over the process of teaching with robots. We understand that the learning process needs to be more controlled but still guided. Newman and DeCaro [25] have found in their empirical study that guidance through worked examples is even better than just exploring using an invention activity. This means that the activity used in our study could also be improved when learners are first introduced to examples how to learn from robotics activities. In addition, they found that completing a pre-test could further increase the learning gain. Thus, we can suggest that in the new experiments, we should make the pre-test results available to the learners so they can understand their learning gaps.

Another explanation of our findings might be that the learners' thinking process needs to be facilitated more in the robotics-based inquiry scenarios. Wang and Wegerif [26] have concluded in their editorial of a special issue on active learning benefits in technology-enhanced education that we need to move from the active-in-behavior process to activein-thinking process in learning with technology. It means that we need to analyze and revise the procedure of applying the learning scenarios so that students focus more on conceptualizing their activities. Following the ideas of open learner modeling, we suggest making the learning process and progress more explicit to the learners [27][28][29][30]. In this case, learning with robots could support the improvement of learning skills, a gap identified by Pedaste and Leijen [8] in using innovative technologies in education. This could also provide good possibilities for self-regulated learning according to the open-ended inquiry approach [31].

\section{CONCLUSION}

In conclusion, we found in our study that inquiry-based activities using robots in learning physics do improve learners' inquiry skills and subject knowledge and skills, but the effect of this intervention is not higher compared to traditional teaching methods. This is valid, at least in case the students are not extensively guided. In addition, we found that the motivation of students is not increased just by using robots, primarily if they have used them previously in learning, and the novelty effect has been faded out. However, further studies are needed to understand in-depth how teachers' activities in the classroom might have an effect on the usability of robots in education and how students' thinking and awareness of the learning process could be improved in order to have a stronger effect on learning outcomes as well.

\section{REFERENCES}

[1] H. Altin and M. Pedaste, "Learning approaches to applying robotics in science education," Journal of Baltic Science Education, vol. 12, pp. 365-377, 2013.

[2] C. L. van Straten, J. Peter, and R. Kuhne, "Child-Robot Relationship Formation: A Narrative Review of Empirical Research," International Journal of Social Robotics, vol. 12, pp. 325-344, 2020.

[3] S. Serholt, L. Pareto, S. Ekstrom, and S. Ljungblad, "Trouble and Repair in Child-Robot Interaction: A Study of Complex Interactions with a Robot Tutee in a Primary School Classroom," Frontiers in Robotics and AI, vol. 7, 2020.

[4] M. Hernandez-de-Menendez, C. E Diaz, and R. Morales-Menendez, "Technologies for the future of learning: state of the art," International Journal of Interactive Design and Manufacturing, vol. 12, pp. 683-695, 2020.

[5] S. Papert, Mindstorms - Children, Computers, and Powerful Ideas, New York: Basic Books, 1980.

[6] R. S. Lindberg, T. H. Laine, and L. Haaranen, "Gamifying Programming Education in K-12: A Review of Programming Curricula in Seven Countries and Programming Games," British Journal of Educational Technology, vol. 50, pp. 1979-1995, 2018.

[7] D. Alimisis, "Robotics in Education \& Education in Robotics: Shifting Focus from," in Proceedings of the 3rd International Conference on Robotics in Education, 2012, pp. 7-14.

[8] M. Pedaste and Ä. Leijen, "How Can Advanced Technologies Support the Contemporary Learning Approach?" in Proceedings of the $18^{\text {th }}$ IEEE International Conference on Advanced Learning Technologies, 2018, pp. 21-23.

[9] M. Pedaste, T. Palts, K. Kori, M. Sõrmus, and Ä. Leijen, "Complex Problem Solving as a Construct of Inquiry, Computational Thinking and Mathematical Problem Solving," in Proceedings of the $19^{\text {th }}$ IEEE International Conference on Advanced Learning Technologies, 2019, pp. 227-231.

[10] M. Pedaste, M. Mäeots, L. A. Siiman, T. de Jong, S. A. van Riesen, E. T. Kamp, C. C. Manoli, Z. C. Zacharia, and E. Tsourlidaki, "Phases of inquiry-based learning: Definitions and the inquiry cycle," Educational Research Review, vol. 14, pp. 47-61, 2015.

[11] T. Palts and M. Pedaste, "A Model for Developing Computational Thinking Skills," Informatics in Education, vol. 19, pp. 113-128, 2020.

[12] J. Fagerlund, P. Hakkinen, M. Vesisenaho, and J. Viiri, "Computational thinking in programming with scratch in primary schools: A systematic review," Computer Applications in Engineering Education, 2020.

[13] J. Jerrim, M. Oliver, and S. Sims, "The Relationship Between Inquiry-based Teaching and Students' Achievement. New Evidence from a Longitudinal PISA Study in England," Learning and Instruction, vol. 61, pp. 35-44, 2019. 
[14] F. L. Luccio, "Learning Distributed Algorithms by Programming Robots," Journal of E-Learning and Knowledge Society, vol. 15, pp. 89-100, 2019.

[15] E. Senft, S. Lemaignan, P. E. Baxter, M. Bartlett, and T. Belpaeme, "Teaching robots' social autonomy from in situ human guidance," Science Robotics, vol. 4, 2019.

[16] R. Ryan and E. Deci, "Self-Determination Theory and the Facilitation of Intrinsic Motivation, Social Development, and WellBeing," The American Psychologist, vol. 55, pp. 68-78, 2000.

[17] J. Vermunt and Y. Vermetten, "Patterns in Student Learning: Relationships Between Learning Strategies, Conceptions of Learning, and Learning Orientations," Educational Psychology Review, vol. 16, pp. 359-384, 2004.

[18] E. Mcauley, T. Duncan, and V. Tammen, "Psychometric Properties of the Intrinsic Motivation Inventory in a Competitive Sport Setting: A Confirmatory Factor Analysis," Research Quarterly for Exercise and Sport, vol. 60, pp. 48-58, 1989.

[19] N. Randall, "A Survey of Robot-Assisted Language Learning (RALL)," ACM Transactions on Human-Robot Interaction, vol. 9, 2020.

[20] S. M. S. Khaksar, B. Slade, J. Wallace, and K. Gurinder, "Critical success factors for application of social robots in special developmental schools Development, adoption and implementation," International Journal of Educational Management, vol. 34, pp. 677696, 2010.

[21] P. Ponce, A. Molina, E. O. L. Caudana, G. B. Reyes, and N. M. Parra, "Improving education in developing countries using robotic platforms," International Journal of Interactive Design and Manufacturing, vol. 13, pp. 1401-1422, 2019.

[22] A. Jackson, N. Mentzer, and R. Kramer-Bottiglio, "Pilot analysis of the impacts of soft robotics design on high-school student engineering perceptions," International Journal of Technology and Design Education, vol. 29, pp. 1083-1104, 2019.
[23] A. Vorholzer and C. Aufschnaiter, "Guidance in Inquiry-based Instruction - An Attempt to Disentangle a Manifold Construct," International Journal of Science Education, vol. 41, pp. 1-16, 2019.

[24] M. Dobber, R. Zwart, M. Tanis, and B. Oers, "Literature Review: The role of the Teacher in Inquiry-based Education," Educational Research Review, vol. 22, pp. 194-214, 2017.

[25] P. Newman and M. DeCaro, "Learning by Exploring: How Much Guidance is Optimal?" Learning and Instruction, vol. 62, pp. 49-63, 2019.

[26] M. Wang and R. Wegerif, "From Active-in-Behaviour to Active-inThinking in Learning with Technology," British Journal of Educational Technology, vol. 50, pp. 2067-2777, 2019.

[27] D. Hooshyar, K. Kori, M. Pedaste, and E. Bardone, "The Potential of Open Learner Models to Promote Active Thinking by Enhancing Self-regulated Learning in Online Higher Education Learning Environments," British Journal of Educational Technology, vol. 50, pp. 2365-2386, 2019.

[28] D. Hooshyar, M. Pedaste, K. Saks, Ä. Leijen, E. Bardone, and M. Wang, "Open learner models in supporting self-regulated learning in higher education: A systematic literature review," Computers \& Education, 2020.

[29] L. Al-Shanfari, C. D. Epp, C. Baber, and M. Nazir, "Visualising alignment to support students' judgment of confidence in open learner models," User Modeling and User-Adapted Interaction, vol. 30, pp. 150-194, 2020.

[30] T. van Woezik, R., Rob, and J. Koksma, "Exploring Open Space: A self-directed learning approach for higher education," Cogent Education, vol. 6, 2019.

[31] M. Tissenbaum, "I see what you did there! Divergent collaboration and learner transitions from unproductive to productive states in open-ended inquiry," Computers \& Education, vol. 145, 2020. 